\title{
Isotope signatures in winter moulted feathers predict malaria prevalence in a breeding avian host
}

\author{
Elizabeth Yohannes • Bengt Hansson • Raymond W. Lee • \\ Jonas Waldenström · Helena Westerdahl · \\ Mikael Åkesson · Dennis Hasselquist · Staffan Bensch
}

Received: 22 February 2008 / Accepted: 22 August 2008 / Published online: 23 September 2008

(C) The Author(s) 2008. This article is published with open access at Springerlink.com

\begin{abstract}
It is widely accepted that animal distribution and migration strategy might have co-evolved in relation to selection pressures exerted by parasites. Here, we first determined the prevalence and types of malaria blood parasites in a breeding population of great reed warblers Acrocephalus arundinaceus using PCR. Secondly, we tested for differences in individual feather stable isotope signatures $\left(\delta^{13} \mathrm{C}, \delta^{15} \mathrm{~N}, \delta \mathrm{D}\right.$ and $\left.\delta^{34} \mathrm{~S}\right)$ to investigate whether malaria infected and non-infected birds had occupied different areas in winter. We show that birds moulting in Afro-tropical habitats with significantly higher $\delta^{13} \mathrm{C}$ and $\delta^{15} \mathrm{~N}$ but lower $\delta \mathrm{D}$ and $\delta^{34} \mathrm{~S}$ values were more frequently infected with malaria parasites. Based on established patterns of isotopic distributions, our results indicate that moulting sites with higher incidence of malaria are generally drier and situated further to the north in West Africa than sites with lower
\end{abstract}

Communicated by Christopher Johnson.

\section{E. Yohannes}

Behavioural Ecology and Evolutionary Genetics,

Max Planck Institute for Ornithology, P.O. Box 1564,

82305 Starnberg (Seewiesen), Germany

e-mail: yohannes@erl.orn.mpg.de

B. Hansson · H. Westerdahl - M. Åkesson - D. Hasselquist .

S. Bensch $(\square)$

Department of Ecology, Lund University,

Ecology Building, 22362 Lund, Sweden

e-mail: Staffan.Bensch@zooekol.lu.se

\section{R. W. Lee}

School of Biological Sciences, Washington State University, Pullman, WA 99164-4236, USA

\section{J. Waldenström}

Section for Zoonotic Ecology and Epidemiology,

University of Kalmar, 39182 Kalmar, Sweden incidence of malaria. Our findings are pertinent to the general hypothesis that animal distribution and particularly avian migration strategy might evolve in response to selection pressures exerted by parasites at different geographic scales. Tradeoffs between investment in energy demanding life history traits (e.g. migration and winter moult) and immune function are suggested to contribute to the particular choice of habitat during migration and at wintering sites.

Keywords Stable isotopes - Bird migration ·

Great reed warbler $\cdot$ Moult $\cdot$ Avian malaria

\section{Introduction}

Since many long-distance migratory bird species cross ecological barriers using long and non-stop flights, such barriers might have minor effects on their patterns of winter distribution. In such species, other ecological or biological factors, such as the selection pressure exerted by pathogenic agents, may play a profound role in determining habitat selection and species ranges (e.g. Brown et al. 1996; Piersma 1997). Due to their higher mobility, migrating birds that breed at northern latitudes and winter in tropical regions have a higher likelihood of exposure to malaria parasites than non-migrating resident species (Waldenström et al. 2002; Fallon et al. 2005). The prevalence of avian malaria parasites (genera Haemoproteus and Plasmodium) has been shown to differ between habitats and closely located areas (Freeman-Gallant et al. 2001; Bensch and Åkesson 2003; Wood et al. 2007) and even at a micro-habitat scale, e.g. in relation to cavity or colony nest height (Garvin and Remsen 1997).

Blood parasites that succeed in escaping the host's immune system could impose strong fitness costs on their 
host (Valkiūans 2005; Zehtindjiev et al. 2008). Complementary to evolving a protective immune system, migrating hosts can defeat parasites by evolving 'avoidance behaviour' such as selecting areas or niches that have lower densities of possible pathogenic reservoirs (e.g. closely related resident species) or avoiding biomes that support higher vector densities (Piersma 1997; Hasselquist 2007).

Stable isotope composition of animal tissues has been widely applied to track migration patterns and distribution (reviewed in: Hobson 1999; Rubenstein and Hobson 2004). Briefly, isotopic ratios of the local environment are incorporated into the organism during nutrient uptake and pass to higher consumers through ecological food chains (De Niro and Epstein 1978). Tissues synthesised in such locations can be used to infer localised and small- to large-scale habitat-specific signals. The relative amount of stable carbon $\left(\delta^{13} \mathrm{C}\right)$, nitrogen $\left(\delta^{15} \mathrm{~N}\right)$ and sulphur $\left(\delta^{34} \mathrm{~S}\right)$ isotopes in plant and animal tissues can be used to assess xeric versus mesic or marine versus freshwater ecosystems or trophic position in food webs (e.g. Minagawa and Wada 1984; Marra et al. 1998). Global patterns of deuterium ( $\delta \mathrm{D}$ or $\left.\delta^{2} \mathrm{H}\right)$ in rainfall that transmit through the local food web provides a mechanism to track animal movements within and between continents (e.g. Hobson 2003).

The great reed warbler (Acrocephalus arundinaceus) is a long-distance migrant that breeds in reed marshes in Europe and Asia and winters in tropical Africa, in habitats ranging from swamp vegetation to dry low and open scrublands far from water (Cramp 1992). The southward migration of this species is known to occur in two stages. Birds from northern Europe leave their breeding grounds in August but interrupt migration and undergo a complete moult (flight and body feathers) during the first half of the winter (September-December) in sub-Saharan West Africa (Bensch et al. 1991; Hedenström et al. 1993). When the moult is completed, they recommence migration (second stage) to more southerly wintering areas. During migration, winter and moult, the species is exposed to different habitats and a high diversity of Afro-tropical malaria parasites (Waldenström et al. 2002; Hellgren et al. 2007a). Studies of great reed warblers breeding in south Central Sweden recorded 17 lineages of malaria parasites, most of which have transmission in Africa (Bensch et al. 2007; Hasselquist 2007; Hellgren et al. 2007a). Ringing recoveries from this Swedish study site indicate that the moulting range extends from the Ivory Coast in the west to Chad in the east (Fig. 1).

The objective of this study was to investigate the link between the choice of wintering area and malaria prevalence. We used feather stable isotope signatures to track whether great reed warblers wintering in different areas show different patterns of malaria parasite prevalence (though they are sympatric at their breeding grounds).
Although little is known on the temporal overlap of migration, moult and malaria infection during the winter, we propose two alternative (but not mutually exclusive) spatio-temporal patterns of wintering/moulting area choice:

1. Habitat separation-a parapatric situation where individual birds rely on different moulting habitats that may abut by an ecotone but do not entirely overlap, i.e. biomes characterised by varying conditions for transmission of malaria.

2. Geographic separation - an allopatric situation where individual birds moult and acquire malaria parasites in different physically separated areas, i.e. exhibit nonoverlapping, distinct winter distribution with different levels of malaria transmission.

To distinguish between the two alternatives, we compared the known patterns of regional isotopic distributions to the results of the four elements considered in the study. Most tropical plants that employ $\mathrm{C}_{4}$ photosynthesis have a mean $\delta^{13} \mathrm{C}$ value around $-12.5 \%$. In contrast, $\mathrm{C}_{3}$ plants associated with cooler, moister habitats have more depleted $\delta^{13} \mathrm{C}$ values (on average: $-27 \%$ ). $\mathrm{C}_{3} / \mathrm{C}_{4}$ plant abundance in subSaharan Africa is assumed to follow a rapid gradient between ca. $5-15^{\circ} \mathrm{N}$ (Still et al. 2003; Still, personal communication) with the highest proportion of $\mathrm{C}_{4}$ plants in a band around $10^{\circ} \mathrm{N}$ of the equator. Most terrestrial plants have mean $\delta^{15} \mathrm{~N}$ range of $3-15 \%$, but there is a strong negative correlation between aridity and $\delta^{15} \mathrm{~N}$, particularly in Africa (e.g. Lajtha and Michener 1994; Ehleringer and Cooper 1988; Cerling et al. 1998). However, $\delta^{15} \mathrm{~N}$ values often vary within regions between nearby habitats (Lajtha and Michener 1994). Environment $\delta$ D fractions are temperature-dependent, and a strong spatial correlation exists between the annual mean temperature and the mean isotopic ratio $\delta \mathrm{D}$ in precipitation (e.g. Petit et al. 1999). Terrestrial birds often have $\delta^{34} \mathrm{~S}$ values less than $+10 \%$, whereas animals from more marine/coastal areas have values falling between +16 and $+18 \%$ o. $\delta^{34} \mathrm{~S}$ values register the proximity of the diet to a marine source (also known as the 'sea spray' effect; for review and control experiments, see Richards et al. 2003).

Based on the different expectations for the four elements on the relationships between isotopic values, habitat and geography, we derived the following predictions that would discriminate between the above hypotheses. If the infected and non-infected birds were moulting in the same geographical area but in different habitats (parapatric situation), we would expect differences in $\delta^{13} \mathrm{C}$ and $\delta^{15} \mathrm{~N}$ but not in $\delta \mathrm{D}$ and $\delta^{34} \mathrm{~S}$ (supporting hypothesis 1). This is because the same geographical region is expected to have the same rainfall pattern $(\delta \mathrm{D})$ and be exposed to a similar influence from a marine environment $\left(\delta^{34} \mathrm{~S}\right)$. Hence, if infected and non-infected birds differ in $\delta \mathrm{D}$ and/or in $\delta^{34} \mathrm{~S}$, it would 
Fig. 1 Ringing recoveries of migratory great reed warblers (Acrocephalus arundinaceus) reported outside the breeding site at lake Kvismaren, south Central Sweden. Dots represent ringing and recovery sites. Connecting lines do not strictly reflect the migratory route and direction. Square dots represent winter study sites of great reed warblers in sub-Saharan Africa. At Navrongo, birds moult between September and December whereafter they leave the area (Hedenström et al. 1993). At Tafo, only a few birds occur during moult, but numbers increase from December when freshly moulted birds arrive which stay until March (Hedenström et al. 1993). At Luluabourg in southern Democratic Republic of Congo, birds arrive in fresh plumage during December and stay until March (De Roo and Deheegher 1969)

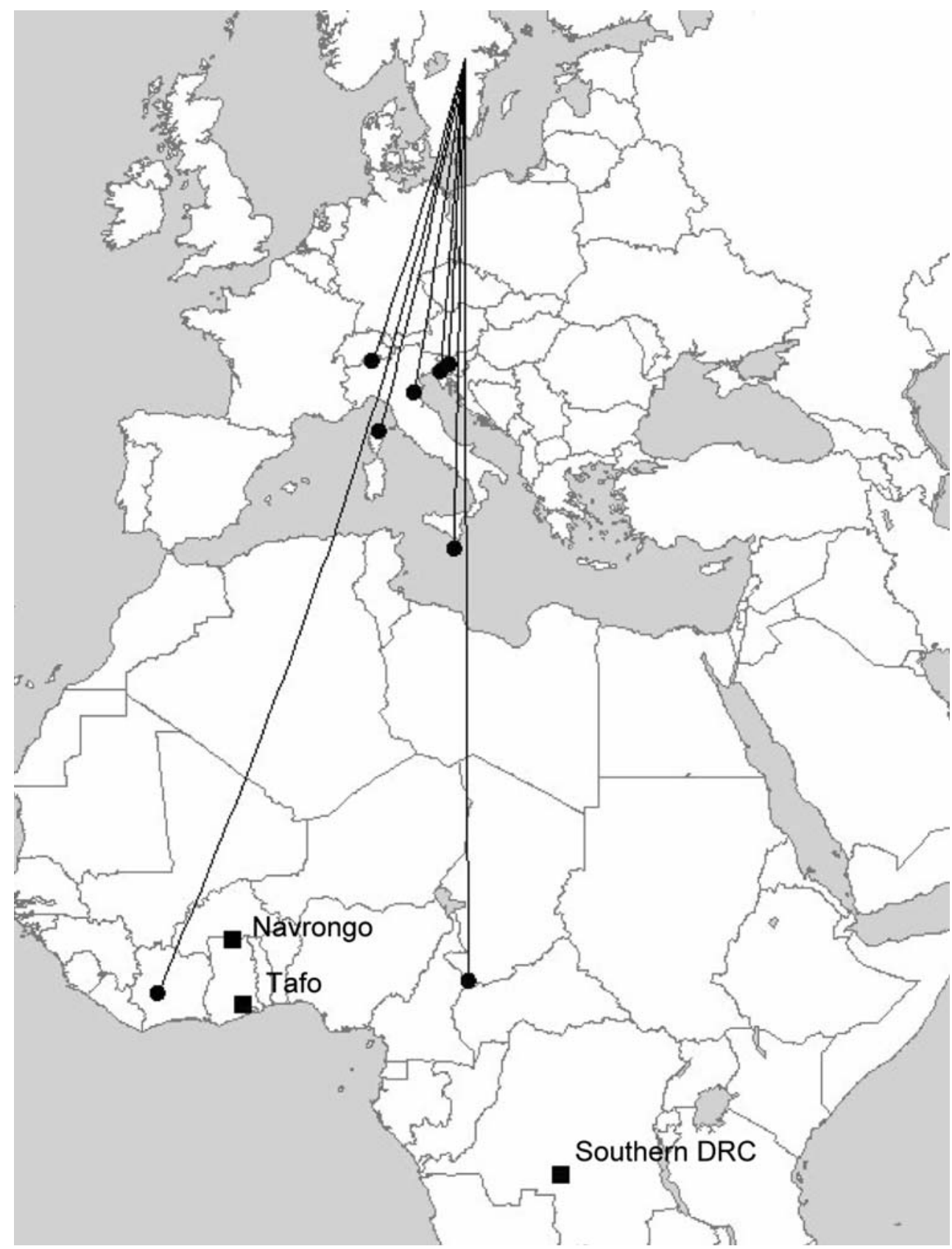

support the geographic separation hypothesis (2), i.e. that they have moulted in different areas (allopatric situation).

\section{Materials and methods}

We detected the prevalence and types of malaria blood parasites (mainly three species that have their transmission strictly in Africa: GRW1, Haemoproteus payevskyi; GRW2, Plasmodium ashfordi and GRW4, Plasmodium relictum) using PCR technique, and determined whether individuals were infected or not infected (Waldenström et al. 2004; Bensch et al. 2007). From each bird screened for malaria, we analysed tail feathers (moulted in Africa) for stable isotopes $\left(\delta^{13} \mathrm{C}, \delta^{15} \mathrm{~N}\right.$ and $\left.\delta \mathrm{D}\right)$ to investigate the relationship between winter moulting habitats (inferred from feather isotope values) and malaria prevalence. A previous study on the same great reed warbler population showed significant repeatability in all three elements, demonstrating that individual birds tend to return to the same moulting area in successive years (Yohannes et al. 2008). To extract further information on habitat use and geographical origin, we analysed stable sulphur $\left(\delta^{34} \mathrm{~S}\right)$ isotopes on a subset of the feather samples $(n=40)$, an element not previously investigated in Afro-tropical migratory birds. 
Sample collection

Between spring 1999 and 2004, we trapped birds using mist-nets and collected blood $(\approx 20 \mu \mathrm{l}$ blood from the brachial vein), and feathers (third outermost tail) from 201 great reed warblers breeding at lake Kvismaren $\left(59^{\circ} 10^{\prime} \mathrm{N}\right.$, $15^{\circ} 25^{\prime} \mathrm{E}$ ) in south Central Sweden. For details of the study population and field methods see Bensch et al. (1998) and Hasselquist (1998). Each individual was marked with a unique combination of three coloured plastic and one aluminium ring.

Genetic analysis

\section{PCR amplification and malaria screening}

Blood samples were stored in $500 \mu \mathrm{l}$ SET-buffer, and DNA was extracted using a standard phenol-chloroform procedure as previously described (Waldenström et al. 2002). Individual samples were screened for parasites using a nested PCR protocol (primer pair 1: HAEMNF and HAEMNR2; primer pair 2: HAEMF and HAEMR2) targeting a 479-bp fragment (excluding primers) of the parasite cytochrome $b$ gene (Waldenström et al. 2004; Bensch et al. 2007). We did direct sequencing with the HAEMF primer of positive reactions and loaded these on an ABI PRISM 310 sequencing robot (Applied Biosystems). This approach allows precise identification of parasitic lineages even when identical parasites occur in different avian host species (Hellgren et al. 2007b). Samples with mixed infections were resolved by TA-cloning of PCR products (Pérez-Tris and Bensch 2005).

Stable isotope measurements

\section{Carbon and nitrogen}

Cleaned subsamples of approximately $0.5 \mathrm{mg}$ of feather were weighed into small tin cups and combusted in a Eurovector (Milan, Italy) elemental analyser. The resulting $\mathrm{N}_{2}$ and $\mathrm{CO}_{2}$ gases were separated by gas chromatography and admitted into the inlet of a Micromass (Manchester, UK) Isoprime isotope ratio mass spectrometer (IRMS) for determination of ${ }^{15} \mathrm{~N} /{ }^{14} \mathrm{~N}$ and ${ }^{13} \mathrm{C} /{ }^{12} \mathrm{C}$ ratios. Measurements are reported in $\delta$-notation relative to the PDB for carbon and atmospheric $\mathrm{N}_{2}$ standard in parts per thousand deviations $\left(\% o\right.$ ). The standard for $\delta^{15} \mathrm{~N}$ is atmospheric nitrogen, and for $\delta^{13} \mathrm{C}$ is Peedee belemnite (PCB). One egg albumin was used as a laboratory standard for every 11 unknowns in sequence. Hundreds of replicate assays of internal laboratory standards (albumen) indicate measurement errors (SD) of $\pm 0.2 \%$ and $\pm 0.5 \%$ o for $\delta^{13} \mathrm{C}$ and $\delta^{15} \mathrm{~N}$, respectively.

\section{Deuterium}

Deuterium measurements on feathers and standards were performed on $\mathrm{H}_{2}$-derived Elemental Analyser-Isotope Ratio Mass Spectrometry (EA-IRM) calibrated and controlled against standard reference material. Cleaned and dried feather samples filled on silver capsules were left open for a period of more than 4 days to allow sample exchangeable hydrogen to equilibrate with the moisture in the laboratory air. Moreover, multiple samples of BWB-II (whale baleen) with a known non-exchangeable $\delta 2 \mathrm{HV}$ SMOW value and our eggshell membrane standard, independently measured by Len Wassenaar, NWRI, Saskatoon, Canada, were analysed. Multiple keratin replicate standards, with known non-exchangeable $\delta \mathrm{D}$ values, were used for correcting uncontrolled isotopic exchange between samples and ambient water vapour (Wassenaar and Hobson 2000). Thus, values reported here are equivalent to nonexchangeable feather hydrogen (Wassenaar and Hobson 2003).

\section{Sulphur}

Analysis was undertaken by EA-IRMS using tin capsules containing reference (barium sulphate and silver sulphide) or sample material (feathers cut into a powder, in situ) plus vanadium pentoxide catalyst. Barium sulphate and whale baleen were measured as quality control check samples during sample analysis.

Data analysis

A one-way ANOVA followed by Scheffe's post hoc test was performed to detect differences between years (19992004). Due to limited data from different years for $\delta^{34} \mathrm{~S}$, this test was done for feather $\delta^{13} \mathrm{C}, \delta^{15} \mathrm{~N}$ and $\delta \mathrm{D}$ only. Based on results of parasite screening, individual birds were scored as either positive (1) or negative (0) for malaria. We used infection (i.e. malaria infected vs noninfected individuals) as a grouping variable, and applied Student's $t$ test (with a Bonferroni correction to the probability threshold for significance due to multiple comparisons) on the null hypothesis that the mean feather $\delta^{13} \mathrm{C}$, $\delta^{15} \mathrm{~N}, \delta \mathrm{D}$ and $\delta^{34} \mathrm{~S}$ values of the two groups are equal. The joint relationship of the three isotopes and malaria parasites (presence or absence) was tested with logistic regression. We applied Multivariate analysis of variance (MANOVA) to reveal possible associations between feather isotope values and the three most common avian malaria parasites (GRW1, GRW2, and GRW4). Feather isotope variables were normally distributed (KolmogorovSmirnov test: $P>0.05$ ). 
Table 1 Six years summary of winter grown feather stable isotope $\left(\delta^{13} \mathrm{C}, \delta^{15} \mathrm{~N}\right.$ and $\left.\delta \mathrm{D}\right)$ values of great reed warblers (Acrocephalus arundinaceus) controlled at a Swedish breeding ground

\begin{tabular}{llll}
\hline Year & \multicolumn{4}{l}{ Feather stable isotopes $($ mean $\pm \mathrm{SE}, n)$} \\
\cline { 2 - 4 } & $\delta^{13} \mathrm{C}$ & $\delta^{15} \mathrm{~N}$ & $\delta \mathrm{D}$ \\
\hline 1999 & $-16.10 \pm 0.54(40)$ & $9.32 \pm 0.19(40)$ & $-66.13 \pm 1.13(41)$ \\
2000 & $-15.57 \pm 0.36(31)$ & $9.31 \pm 0.28(31)$ & $-68.53 \pm 1.22(30)$ \\
2001 & $-16.82 \pm 0.55(27)$ & $8.43 \pm 0.33(26)$ & $-63.35 \pm 1.13(26)$ \\
2002 & $-16.41 \pm 0.65(30)$ & $9.09 \pm 0.36(31)$ & $-65.59 \pm 2.26(29)$ \\
2003 & $-16.32 \pm 0.59(31)$ & $8.58 \pm 0.30(31)$ & $-66.42 \pm 2.30(31)$ \\
2004 & $-15.12 \pm 0.66(24)$ & $8.76 \pm 0.40(24)$ & $-65.04 \pm 1.79(24)$
\end{tabular}

\section{Results}

The $\delta^{13} \mathrm{C}, \delta^{15} \mathrm{~N}$ and $\delta \mathrm{D}$ values in the feathers $(n=176)$ were only weakly correlated $\left(\delta^{13} \mathrm{C}\right.$ and $\delta^{15} \mathrm{~N}, r=0.111$, $P=0.14 ; \delta^{13} \mathrm{C}$ and $\delta \mathrm{D}, r=0.114, P=0.13 ; \delta^{15} \mathrm{~N}$ and $\delta \mathrm{D}$, $r=-0.146, P=0.05)$. The ANOVAs revealed no significant year effect on isotopic values $\left(\delta^{13} \mathrm{C}: F_{5,181}=0.98\right.$, $\delta^{15} \mathrm{~N}: F_{5,180}=1.57$ and $\delta \mathrm{D}: F_{5,179}=0.97, P>0.1$ for each), hence we pooled samples from the six study years (Table 1).

Mean $\delta^{13} \mathrm{C}, \delta^{15} \mathrm{~N}$ and $\delta \mathrm{D}$ values in the feathers of birds with malaria were significantly different as compared to the birds without malaria $\left(\delta^{13} \mathrm{C}: t=-2.77, P=0.01, n=160\right.$; $\delta^{15} \mathrm{~N}: \quad t=-2.87, \quad P<0.01, \quad n=160 ; \quad \delta \mathrm{D}: \quad t=-3.48$, $P<0.001, n=158$; Fig. 2. A logistic regression model with malaria infection (positive or negative) as the response variable and the three element ratios as independent variables was overall highly significant $\left(\chi_{3}^{2}=28.8, P<0.001\right)$ and each of the elements contributed significantly to the model $\left(\delta^{13} \mathrm{C}, \beta=0.19, P=0.002 ; \delta^{15} \mathrm{~N}, \beta=0.24, P=0.029\right.$; $\delta \mathrm{D}, \beta=-0.07, P=0.001)$, Table 2. Likewise, mean $\delta^{34} \mathrm{~S}$ values in the feathers of malaria-infected birds were significantly different than malaria-free birds $\left(\delta^{34} \mathrm{~S}: t=5.44\right.$, $P<0.001, n=40$ ).

Among the 87 individuals scored positive for malaria infection, we detected GRW1, GRW2 and GRW4 in 39, 12 and $32 \%$ of the infected population, respectively. A MANOVA revealed no significant relationship between feather isotope values and malaria type $\left(F_{6,118}=1.19\right.$, $P=0.31$ ).

\section{Discussion}

We found marked differences in isotopic signatures for each of the four elements when comparing infected and non-infected birds. Great reed warblers moulting in tropical habitats with relatively higher $\delta^{13} \mathrm{C}$ and $\delta^{15} \mathrm{~N}$, and lower $\delta \mathrm{D}$
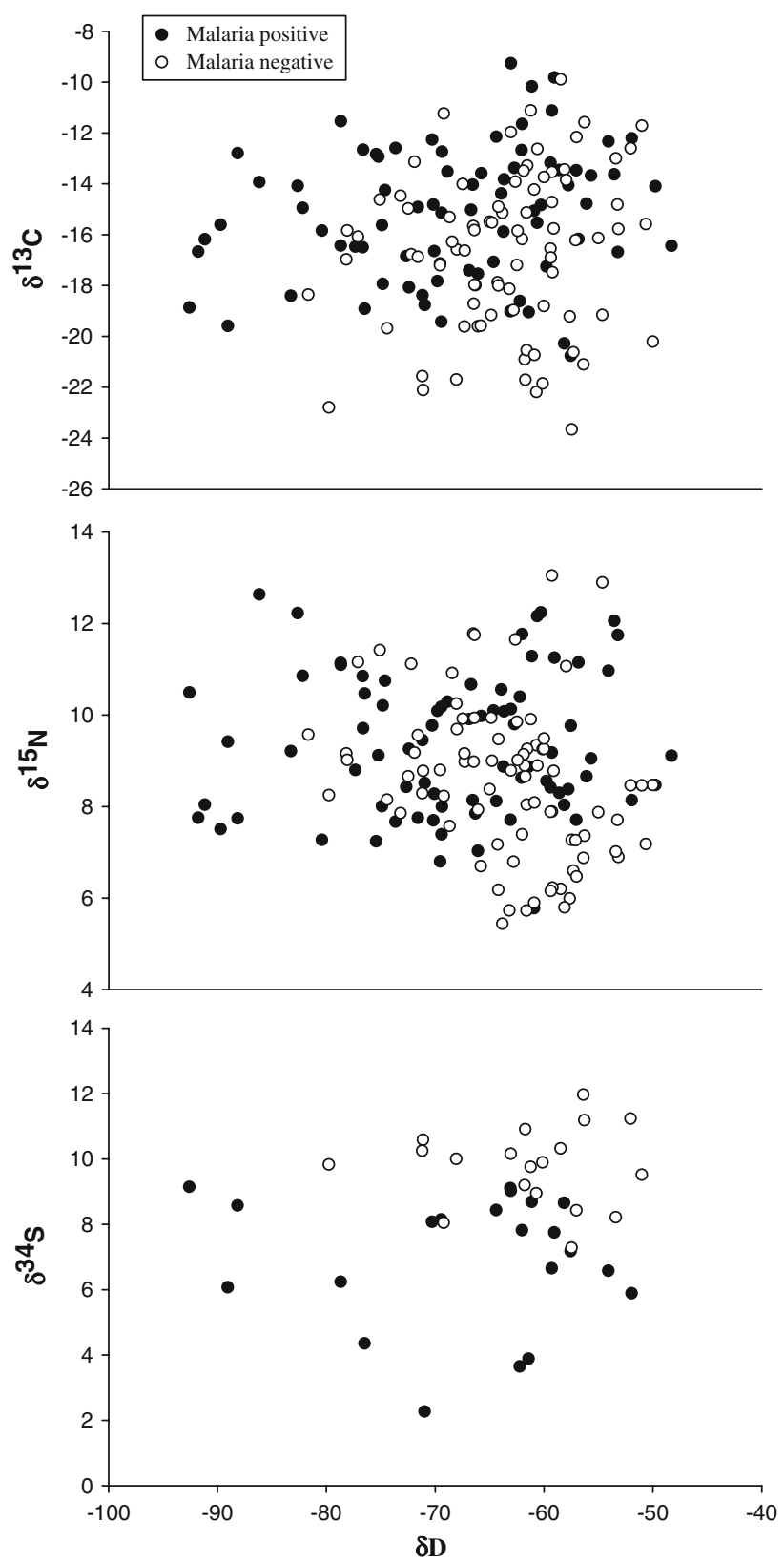

Fig. 2 Feather $\delta^{13} \mathrm{C}, \delta^{15} \mathrm{~N}, \delta \mathrm{D}$ and $\delta^{34} \mathrm{~S}$ values of malaria infected/ positive (1) and malaria free/negative (0) great reed warblers. Birds moulting in areas with relatively higher $\delta^{13} \mathrm{C}$ and $\delta^{15} \mathrm{~N}$ but lower $\delta \mathrm{D}$ and $\delta^{34} \mathrm{~S}$ values harboured a higher rate of malaria parasites. Analysis of $\delta^{34} \mathrm{~S}$ values was carried out on 40 feather samples that were known to have the highest $\delta^{13} \mathrm{C}$ values $(n=21 ; 11$ malaria infected and 10 malaria free) and lowest $\delta^{13} \mathrm{C}$ values $(n=19 ; 10$ malaria infected and 9 malaria free)

and $\delta^{34} \mathrm{~S}$ values have a higher incidence of malaria infections (Fig. 2). This result shows that birds infected by malaria parasites have moulted in different geographical areas than the non-infected birds. Moreover, the strong differences in $\delta^{13} \mathrm{C}$ and $\delta^{15} \mathrm{~N}$ suggest that these regions offer different habitats. Our results also show that parasite com- 
Table 2 Results from multiple logistic regression analyses between infection status of malaria parasites ( 0 or 1$)$ and feather stable isotope signatures in great reed warblers. The stable isotope values were $Z$-transformed prior to analyses in order for effect sizes to be compared

\begin{tabular}{lrll}
\hline Elements & $\mathrm{B}$ & $\mathrm{SE}$ & $P$ \\
\hline \multicolumn{2}{l}{ Three elements $(n=159)$} & & \\
$\delta^{13} \mathrm{C}$ & 0.606 & 0.197 & 0.002 \\
$\delta^{15} \mathrm{~N}$ & 0.401 & 0.184 & 0.029 \\
$\delta \mathrm{D}$ & -0.637 & 0.196 & 0.001 \\
Four elements $(n=40)$ & & \\
$\delta^{13} \mathrm{C}$ & 0.284 & 0.350 & 0.417 \\
$\delta^{15} \mathrm{~N}$ & 1.483 & 0.867 & 0.087 \\
$\delta \mathrm{D}$ & -0.880 & 0.665 & 0.186 \\
$\delta^{34} \mathrm{~S}$ & -4.029 & 1.542 & 0.009 \\
\hline
\end{tabular}

position is not related to moulting area. Hence, regardless of the type of parasite involved, the mechanisms employed to contract, avoid or reduce malaria parasites appears similar.

The significantly higher $\delta^{13} \mathrm{C}$ and $\delta^{15} \mathrm{~N}$ values in birds infected with avian malaria parasites suggests that these feathers have been grown in a $\mathrm{C}_{4}$-dominated and drier habitat than the feathers from uninfected birds. Malaria infected birds had on average ca. $5 \%$ o lower $\delta \mathrm{D}$ values in their feathers compared to non-infected birds. The fact that there is a difference in both $\delta \mathrm{D}$ and $\delta^{34} \mathrm{~S}$ implies that birds do not segregate into different habitats within the same geographical region, supporting the allopatric situation (hypothesis 2).

In terrestrial systems, feather $\delta \mathrm{D}$ correlate with the local precipitation of $\delta \mathrm{D}$ during the growing season at the birds' moult location (Hobson and Wassenaar 1997). Hence, our data suggest that infected birds have moulted in different geographical regions. The observation of lower $\delta \mathrm{D}$ values in malaria-infected birds is not consistent with the interpretation that these are from drier habitats (since dry habitats are expected to show higher $\delta \mathrm{D}$ values). The result could be explained if the infected birds had been moulting at higher altitudes than non-infected birds, but this is rather unlikely given the small altitude variation in the species' West African wintering range (Fig. 1). An alternative explanation is that the depleted $\delta \mathrm{D}$ values in the malaria-infected birds reflect moulting sites more inland, i.e. further north. Results of feather $\delta^{34} \mathrm{~S}$ values agree with this explanation. Malaria infected birds showed a lower $\delta^{34} \mathrm{~S}$ value (mean $\pm \mathrm{SE}$ : $6.96 \% \circ \pm 0.44, n=21$ ) compared to malaria negative birds (mean \pm SE: $9.77 \% \circ \pm 0.28, n=19$ ) (Fig. 2). These results support the hypothesis that birds moult in geographically separate areas and possibly that the malaria-infected birds are moulting further inland and to the north.

Generally, the results imply that our study population moult in tropical environments dominated by $\mathrm{C}_{4}$ plants. However, the wide range of $\delta^{13} \mathrm{C}$ signatures found in the great reed warbler feathers (range between -23.67 and $-9.26 \%$ ) suggests that the birds moult across a variable gradient of $\delta^{13} \mathrm{C}$ signatures. Based on earlier ringing recovery data (Fig. 1; Bensch 1993) and studies of moulting time and sites in Ghana (Hedenström et al. 1993), our study population is likely to have replaced their feathers in West Africa between $8^{\circ} \mathrm{N}$ and $17^{\circ} \mathrm{N}$ latitude and $10^{\circ} \mathrm{W}$ and $20^{\circ} \mathrm{E}$ longitude. Feather stable isotope values in this study corresponds very well with values reported for a great reed warbler feather moulted in West Africa, reported by Neto et al. (2006). Aquatic warblers (Acrocephalus paludicola) also moult in sub-Saharan West Africa in similar habitats as the great reed warbler. A study based on feathers collected at European breeding grounds (Pain et al. 2004) showed that aquatic warblers have $\delta^{13} \mathrm{C}$ values more similar to the malaria-free birds and $\delta^{15} \mathrm{~N}$ and $\delta \mathrm{D}$ values more similar to the infected ones. Aquatic warblers are believed to moult in the West African floodplains of Mauritania, Mali, and Senegal (Pain et al. 2004), i.e. in the northern part of Sahel, overlapping the supposed moulting range for great reed warblers.

Results of this study indicate that great reed warblers moulting in habitats dominated with $\mathrm{C}_{4}$ plants and with a dry and warm climate have the highest infection rate. Avian malaria prevalence is associated with the availability of vectors and suitable reservoirs (Valkiūans 2005). An optimal condition created by a combination of such factors may account for inter- and intra-specific habitat, geographic and latitudinal variation in parasite prevalence (e.g. Tella et al. 1999). The winter habitat of the great reed warbler ranges from swampy areas to dry scrublands (Cramp 1992). This probably allows individuals of this species to occupy habitats associated with varying parasite prevalence. Variation in habitat used could either be the result of within-species variation in climatic preferences, or the result of dominance relationships, with subdominant birds forced to use drier, more malaria-exposed areas to the north (see Marra et al. 1998).

\section{Conclusion}

We found that the prevalence of avian malaria parasites in a breeding population of great reed warblers differs depending on the winter moulting area. From present knowledge of the distribution of isotopes, our results suggest that birds moulting at drier sites situated further north in West Africa have a higher incidence of malaria than birds moulting at wetter sites closer to the coast. However, the present study cannot exclude that birds obtain the infections after the moulting season when they might be in more southern areas of Africa (De Roo and Deheegher 1969; Hedenström et al. 1993). However, if that is the case, areas used during late winter must be at least partly determined by the moulting 
areas. Similar choices of wintering area and malaria prevalence may be an important factor driving assortative mating among individuals with identical (inherited) migration directions and distances. Future studies that apply habitatspecific stable isotope signatures might help to determine whether separated wintering populations of great reed warbler pair assortatively on their breeding grounds.

Acknowledgments We are grateful to Bo Nielsen, Anna-Karin Olsson, Martin Stervander, Debora Arlt and Örjan Östman for assistance in the field and to Kenji Adachi for assistance in the laboratory. We thank Hubert Schwabl and the late Eberhard Gwinner for their generous support during the study. Financial support was received from the Max Planck Society (E.Y.), NSF Grant DBI-011620 (R.L.) and the Swedish Research Council (S.B., D.H.), the Swedish Research Council for Environment, Agricultural Sciences and Spatial Planning (S.B., D.H.), Lunds Djurskyddsfond (D.H., M.Å., B.H.) and the Carl Tryggers Stiftelse (D.H.).

Open Access This article is distributed under the terms of the Creative Commons Attribution Noncommercial License which permits any noncommercial use, distribution, and reproduction in any medium, provided the original author(s) and source are credited.

\section{References}

Bensch S, Åkesson S (2003) Temporal and spatial variation of hematozoans in Scandinavian willow warblers. J Parasitol 89:388391

Bensch S, Hasselquist D, Hedenström H, Ottosson U (1991) Rapid moult among Palaearctic migrants in Ghana - an adaptation to the oncoming dry season. Ibis 133:47-52

Bensch S, Hasselquist D, Nielsen B, Hansson B (1998) Higher fitness for philopatric than for immigrant males in a semi-isolated population of great reed warblers. Evolution 52:877-883

Bensch S, Waldenström J, Jonzén N, Westerdahl H, Hansson B, Sejberg D, Hasselquist D (2007) Temporal dynamics and diversity of avian malaria parasites in a single host species. J Anim Ecol $76: 112-122$

Brown HH, Stevens GC, Kaufman DM (1996) The geographical range: size, shape, boundaries and internal structure. Annu Rev Ecol System 27:597-623

Cerling TE, Ehleringer JR, Harris JM (1998) Carbon dioxide starvation, the development of $\mathrm{C} 4$ ecosystems, and mammalian evolution. Philos Trans R Soc Lond B 353:159-171

Cramp S (1992) Birds of the western Palaearctic. Vol. VI. Warblers. Oxford University Press, Oxford

De Niro MJ, Epstein S (1978) Carbon isotopic evidence for different feeding patterns in two hyrax species occupying the same habitat. Science 201:906-908

De Roo A, Deheegher J (1969) Ecology of the great reed warbler Acrocephalus arundinaceus (L.), wintering in the southern Congo savanna. Gerfaut 59:260-275

Ehleringer JR, Cooper TA (1988) Correlation between carbon isotope ratio and microhabitat in desert plants. Oecologia 76:562566

Fallon SM, Bermingham E, Ricklefs RE (2005) Host specialization and geographic localization of avian malaria parasites: a regional analysis in the Lesser Antilles. Am Nat 165:466-480

Freeman-Gallant C, O'Connor KD, Breuer ME (2001) Sexual selection and the geography of Plasmodium infection in Savannah sparrows (Passerculus sandwichensis). Oecologia 127:517-521
Garvin MC, Remsen JV (1997) An alternative hypothesis for parasite loads of brightly colored birds: exposure at the nest. Auk 114:179-191

Hasselquist D (1998) Polygyny in great reed warblers: a long term study of factors contributing to male fitness. Ecology 79:23762390

Hasselquist D (2007) Comparative immunoecology in birds: hypotheses and tests. J Ornithol 148 (Suppl 2):S571-S582

Hedenström A, Bensch S, Hasselquist D, Lockwood M, Ottosson U (1993) Migration, stopover and moult of the Great Reed Warbler Acrocephalus arundinaceus in Ghana, West Africa. Ibis 135:177-180

Hellgren O, Waldenström J, Peréz-Tris J, Szöllösi E, Hasselquist D, Krizanauskiene A, Ottosson U, Bensch S (2007a) Detecting shifts of transmission areas in avian blood parasites-a phylogenetic approach. Mol Ecol 16:1281-1290

Hellgren O, Krizanauskiene A, Valkiunas G, Bensch S (2007b) Diversity and phylogeny of mitochondrial cytochrome $b$ lineages from six morphospecies of avian Haemoproteus Haemosporida Haemoproteidae. J Parasitol 93:889-896

Hobson KA (1999) Tracing origins and migration of wildlife using stable isotopes: a review. Oecologia 120:314-326

Hobson KA (2003) Making migratory connections with stable isotopes. In: Berthold P, Gwinner E, Sonnenschein E (eds) Avian migration. Springer, Berlin, pp 379-391

Hobson KA, Wassenaar LI (1997) Linking breeding and wintering grounds of neo tropical migrants using stable $\mathrm{H}$ isotopic analysis of feathers. Oecologia 109:142-148

Lajtha K, Michener RH (1994) Stable isotopes in ecology and environmental science. Blackwell, Oxford

Marra PP, Hobson KA, Holmes RT (1998) Linking winter and summer events in a migratory bird by using stable carbon isotopes. Science 282:884-1886

Minagawa M, Wada E (1984) Stepwise enrichment of ${ }^{15} \mathrm{~N}$ along food chains: further evidence and the relation between ${ }^{15} \mathrm{~N}$ and animal age. Geochim Cosmochim Acta 48:1135-1140

Neto JM, Newton J, Gosler AG, Perrins CM (2006) Using stable isotope analysis to determine the winter moult extent in migratory birds: the complex moult of Savi's warblers Locustella luscinioides. J Avian Biol 37:117-124

Pain DJ, Green RE, Gießing B, Kozulin A, Poluda A, Ottosson U, Flade M, Hilton GM (2004) Using stable isotopes to investigate migratory connectivity of the globally threatened aquatic warbler Acrocephalus paludicola. Oecologia 138:168-174

Pérez-Tris J, Bensch S (2005) Diagnosing genetically diverse avian malaria infections using mixed-sequence analysis and TA-cloning. Parasitology 131:15-23

Petit JR, Jouzel J, Raynaud D, Barkov NI, Barnola J-M, Basile I, Bender M, Chappellaz J, Davis M, Delayque G, Delmotte M, Kotlyakov VM, Legrand M, Lipenkov VY, Lorius C, Pépin L, Ritz C, Saltzman E, Stievenard M (1999) Climate and atmospheric history of the past 420000 years from the Vostok ice core Antarctica. Nature 399:429-436

Piersma T (1997) Do global patterns of habitat use and migration strategies co-evolve with relative investments in immunocompetence due to spatial variation in parasite pressure? Oikos 80:623-631

Rubenstein DR, Hobson KA (2004) From birds to butterflies: animal movement patterns and stable isotopes. Trends Ecol Evol 19:256263

Tella JL, Blanco G, Forero GMG, Gajon A, Donazar JA, Hiraldo F (1999) Habitat, world geographic range and development of hosts explain the prevalence of avian hematozoa at small spatial and phylogenetic range. Proc Natl Acad Sci USA 96:785-1789

Valkiūans G (2005) Avian malaria parasites and other Haemosporidia, 1st edn. CRC, Boca Raton 
Waldenström J, Bensch S, Kiboi S, Hasselquist D, Ottosson U (2002) Cross-species infection of blood parasites between resident and migratory songbirds in Africa. Mol Ecol 11:1545-1554

Waldenström J, Bensch S, Hasselquist D, Östman Ö (2004) A new nested PCR method very efficient in detecting plasmodium and haemoproteus infections from avian blood. J Parasitol 90:191-194

Wassenaar LI, Hobson KA (2000) Stable-carbon and hydrogen isotope ratios reveal breeding origins of red winged blackbirds. Ecol Appl 10:911-916

Wassenaar LI, Hobson KA (2003) Comparative equilibration and online technique for determination of non-exchangeable hydrogen of keratins for use in animal migration studies. Isotopes Environ Health Stud 39:211-217
Wood JM, Cosgrove LC, Wilkin AT, Knowles CLS, Day PK, Sheldon CK (2007) Within-population variation in prevalence and lineage distribution of avian malaria in blue tits, Cyanistes caeruleus. Mol Ecol 16:3263-3273

Yohannes E, Bensch S, Lee WR (2008) Philopatry of winter moult area in migratory Great Reed Warblers Acrocephalus arudinaceus demonstrated by stable isotope profiles. J Ornithol 149:261-265

Zehtindjiev P, Ilieva M, Westerdahl H, Hansson B, Valkiunas G, Bensch S (2008) Dynamics of parasitemia of malaria parasites in a naturally and experimentally infected migratory songbird, the great reed warbler Acrocephalus arundinaceus. Exp Parasitol 119:99-110 